\title{
Versos y discurso. Un acercamiento a la improvisación en el Decimal del huapango arribeño
}

Verses and discourse. An approach to the improvisation in the "Decimal" of Huapango arribeño

Agustín Rodríguez Hernández

Universidad Michoacana de San Nicolás de Hidalgo (Morelia, Michoacán, México) agustin.rguez@tec.mx

\author{
IMPROVISACIÓN POÉTICA Y PERFORMANCE. ASPECTOS ANTROPOLÓGICOS, LITERARIOS Y \\ MUSICALES. \\ MONOGRÁFICO COORDINADO POR MARÍA PILAR PANERO GARCÍA (Universidad de Valladolid)
}

Patrocinado por la Cátedra de Estudios sobre la Tradición (Universidad de Valladolid)

\begin{abstract}
RESUMEN
El presente artículo analiza la improvisación en la tradición del huapango arribeño. Cada pieza arribeña se compone de tres partes, sin embargo, es en la segunda sección llamada Decimal donde se improvisan la glosa y las décimas. Por este motivo, se propone esta sección para el análisis. Además, es necesario destacar que en esta tradición la fiesta de la topada es el lugar idóneo para que se presente el enfrentamiento entre los trovadores. Por esto, se toman como base las décimas de controversia de la topada entre don Cándido Martínez y don Agapito Briones para llevar el hilo conductor del trabajo. Este modo de analizar la improvisación será relevante para conocer cómo se conforma, en primera instancia el discurso de cada uno de los trovadores a lo largo de la topada. Aunado a ello, permitirá apreciar que se puede conjuntar las composiciones de ambos trovadores para entender la topada como un discurso dialógico que encuentra su complementariedad en la contraposición.
\end{abstract}

\footnotetext{
ABSTRACT crossover of both speeches makes the discourse of the "Topada".

PALABRAS CLAVE

topada | improvisación | huapango arribeño | controversia poética

KEYWORDS

topada | improvisation | huapango arribeño | poetic controversy
}

This article analyzes improvisation in the tradition of the "Huapango arribeño". Each composition of "Huapango arribeño" has three parts; however, it is in the second section named "Decimal," where the ten-line stanza is improvised. For this reason, I propose this section for the analysis. In addition, it is necessary to emphasize that in this music-poetic tradition, the festival of the "Topada" is the ideal place for the confrontation between the troubadours to occur. For this reason, I use the ten-line stanza of the poetic controversy between Don Cándido Martinez and Don Agapito Briones. This "Topada" took place in a little town of San Luis Potosí, Mexico, in 1987. This study will show how each troubadour creates his speech. In the end, it is possible to consider that the

\section{Introducción}

El arte de la improvisación desafía nuestros supuestos y herramientas de estudio de la tradición oral. Es un poeta conocido quien improvisa, realiza su labor frente a un público, de tal modo que se puede saber su nombre y se responsabiliza por los versos creados. No hay un autor anónimo, no ha habido tiempo tampoco para que el autor legión haga su labor de permanencia y variación para que la obra perdure más allá de la vida física del improvisador. El proceso de tradicionalización apenas está en ciernes. La obra sale de boca del improvisador con algunas señas de identidad que permiten identificar a la composición como tal: fórmulas, tópicos, estructuras, temas que se adaptan a un estilo, a una estética comunitaria que favorece su aceptación, repetición y, en su caso, variación al momento de recrearlos. Sin embargo, a pesar de estas peculiaridades, la tradición vive en las variantes. A continuación, presento el análisis de versos improvisados en controversia poética en una tradición poético-musical de México que utiliza la glosa en décimas como base de su estructura literaria: el huapango arribeño.

El huapango arribeño es una expresión poético-musical que hunde sus raíces en la zona centro-norte de México en el estado de San Luis Potosí. Su zona de influencia se extiende desde la Zona Media del estado potosino hasta la Sierra Gorda. Al igual que sucede con otras formas de la tradición oral, la región en la que se presenta no conoce de fronteras políticas, sino de aspectos comunitarios compartidos que 
propician la delimitación de la región con otros parámetros. De este modo, las comunidades de estos poblados han hecho suyo el huapango arribeño, lo han transmitido por varias generaciones y lo han compartido con quienes se acercan a conocerlo. Su origen temporal se remonta hacia fines del siglo XIX, en particular, 1898 año en que nace don Francisco Berrones, a quien se le considera el patriarca de la tradición. Sin embargo, él mismo relata haber conocido esta tradición en una controversia poética entre don Eugenio Villanueva y don José Torres (véase Berrones 1988: 21). A pesar de esta anécdota, lo cierto es que aún falta por investigar sobre el origen de la tradición.

Son varias las fiestas que convoca el huapango arribeño, en la actualidad, una de las más importantes es el Festival del Huapango Arribeño y de la Cultura de la Sierra Gorda. Este festival se lleva a cabo en Xichú, Guanajuato los días 29, 30, 31 de diciembre y el 1 de enero de cada año. En esta fiesta se reúnen no solo cultores de huapango arribeño, sino que, con los años, la tradición se ha abierto al diálogo con otras formas de expresión poético musical. Esto ha llevado a cantantes de rap, reggae, y cultores de huapango huasteco hasta el festival de la Sierra Gorda. Asimismo, han llegado a este festival distintos improvisadores provenientes de España e Hispanoamérica: Islas Canarias, Puerto Rico, Cuba, Chile, Uruguay, y Argentina. Así, la fiesta de la topada se revitaliza, no solo por la fuerza comunitaria de la región, sino por entablar un diálogo con otras regiones culturales y hacerlas partícipes de esta experiencia. Este año, 2022, el Festival llegará a su emisión número 40. De este modo, se aprecia la actualidad y relevancia del huapango arribeño, pues ha sabido dialogar con el pasado, convencer al presente y forjar el futuro de la comunidad en torno a la fiesta que lo convoca: la topada.

En una tradición como la del huapango arribeño no hay que buscar la tradicionalización solo en lo poético, en los versos. Es necesario tomar en cuenta que es un arte verbal perfomativo en la que hay otros factores importantes. La música, el baile y la palabra se conjugan en cada una de las presentaciones de los trovadores y en particular en la fiesta máxima del huapango arribeño: la topada. De este modo, hay elementos que permanecen y que varían a la vez. Por ejemplo, el lugar donde se sientan los trovadores es recurrente, pero la forma de construirlo y adornarlo es diferente dependiendo de la comunidad donde se presentan los trovadores. Hay regiones donde todavía se conserva el baile de las parejas donde los varones se colocan en frente de las mujeres. En algunos lugares las tablas de madera que se incrustaban en la tierra han cedido su espacio al concreto, pero el elemento del baile permanece. Habría que puntualizar que, incluso dependiendo de la región, llega a haber variaciones en la forma de bailar. Por su parte, la parte poética conserva temas, fórmulas, estructuras y aun en la aparentemente restrictiva forma de la décima, se encuentran variaciones.

\section{La topada y la improvisación}

En la tradición del huapango arribeño, la controversia poética tiene una serie de reglas y de fases que se cumplen en el transcurso del ritual de la topada. Esta se distingue por tener cuatro partes: Saludo, Fundamento, Bravata y Despedida (1). Sin embargo, es necesario puntualizar que, en realidad, estas secciones no se presentan de forma diferenciada y excluyente, por el contrario, se interpolan en muchas ocasiones. De este modo, el tejido resultante de la controversia presenta una serie de contrapuntos armónicos que enriquecen, desde las diferentes características de cada una de las secciones, la experiencia del auditorio, los bailadores y los trovadores.

Es necesario señalar que en el huapango arribeño son varios los actores que toman un rol protagónico a lo largo de la topada. Sin duda alguna, los más notorios serían los músicos y el trovador. Cada uno de los dos conjuntos de huapango que se enfrentan en la topada está conformado por dos violinistas, un vihuelero y el trovador que toca la quinta huapanguera. Es significativa la cantidad de cordófonos y que la labor primordial de todos sea la ejecución de la música, dado que, en esencia, la topada es un baile comunitario. El trovador y el vihuelero tendrán, además, una segunda función. El primero será quien esté a cargo de cantar e improvisar las distintas glosas en décimas que ha preparado, y aquellas que creará al momento para proponer una suerte de hilo lírico-narrativo en la fiesta. El segundo, será el encargado de cantar los sones que se ejecutan para cerrar la pieza. El huapango arribeño tiene una fuerte tradición dancística. Ha habido algunos bailadores que se han destacado y son reconocidos por la comunidad por su habilidad y compromiso con este tipo de baile. Además de estas tres funciones que se han mencionado, dentro del auditorio hay otro grupo de personas que, ya sea que baile o no, escucha con mucha atención las composiciones de los trovadores y las aprueba, apoyándolos con vítores y hurras, o las rechaza, al omitir refuerzos positivos al final de cada una. 
La pieza arribeña se conforma de tres partes: la Poesía, el Decimal y el Son o Jarabe. Cada intervención de los conjuntos de huapango presentará cada una de estas tres secciones. La estructura poética de las primeras dos es la glosa en décimas; la tercera parte se construye con coplas. Como ya he señalado en otras ocasiones, la Poesía se basa en una glosa de línea y el Decimal es una glosa de cuarteta (2). El reglamento no escrito, sobre el cual basan su labor los trovadores, indica que en el Decimal se improvisan los versos (므).

Ahora bien, vale la pena recordar las cuatro partes de la topada para poner en perspectiva la labor del trovador como improvisador. En el Saludo, la primera glosa en décimas, la de la Poesía, presenta el agradecimiento del trovador por la invitación a participar en la fiesta, se presenta ante el auditorio y ante el otro trovador. Es pertinente destacar que la fiesta tiene como macroestructura la construcción de un discurso con algunos elementos de la retórica clásica. Por ejemplo, hay cierta deferencia para el conjunto contrario y se solicita al auditorio una disculpa anticipada por si hubiera algunos errores en la ejecución, el canto o la composición de los versos (4).

La parte de la Poesía, además, se distingue por ser poesía oralizada, es decir, escrita con anticipación, memorizada y llevada al canto en el momento de la fiesta (5). Es posible que en la glosa se desarrollen temas sobre la bienvenida y la alegría de estar reunidos para la fiesta. En el Decimal, uno de los aspectos más importantes es que la salutación se personaliza con especial énfasis a los organizadores de la topada, figuras sobresalientes de la comunidad o hacia las personas que se acercan a los trovadores a solicitar de forma explícita un saludo (). $)$. Por último, el Son cierra la composición, aunque stricto sensu no sigue la temática de la salutación. La música es el eje principal de la pieza, incluso cuando los ritmos y la melodía varían. Los bailadores intercambian las percusiones de sus pies en contrapunto con la melodía de los violines, a veces siguiendo el ritmo de la guitarra y la vihuela, en ocasiones bailando en controversia con algunos otros bailadores. No hay que olvidar que el reto de la controversia es, en esencia, un juego. Así que ese reto lúdico de los tarangos en los que están los músicos tiene su eco en el espacio donde baila el auditorio (ㄱ). Esto, aunado a que, para aquellas parejas que están en un cortejo amoroso, demostrar que se es mejor bailador que otros asistentes implica también que se es mejor prospecto.

La estructura de la pieza arribeña otorga una dinámica que ayuda a organizar las ideas de la controversia poética. Además, proporciona los elementos fundamentales para identificar el desarrollo del discurso. De este modo, la transición del Saludo al Fundamento se da sin dejar del todo los elementos de la primera sección. Es decir, el requisito principal del Fundamento es que se trate en la glosa en décimas el tema de la fiesta, ya sea que sea una boda, un cumpleaños, un aniversario ejidal, entre otros. Para esta labor, la Poesía es el medio más utilizado. Esto sucede ya que, en el Decimal, al menos al inicio de esta sección, en vez de hablar sobre el tema principal de la fiesta, el trovador seguirá enviando saludos a los asistentes. Es necesario preguntarse la razón de esta estructura. Me parece que es importante que el auditorio no se sienta alejado del trovador. Si bien hablará sobre la fiesta, la relación entre el trovador y el auditorio se estrecha cuando este último se ve reflejado en los versos que se cantan en la fiesta.

La tercera parte de la topada es la Bravata. Nuevamente, la Poesía se convierte en el eje fundamental para identificar cada una de las etapas de la pieza arribeña. La característica fundamental de esta sección es el reto hacia el otro trovador. Se plantean una serie de preguntas hacia el contrincante con el deseo de ponerlo en aprietos y que le sea muy difícil responder. De este modo, ante el auditorio se verá que no tiene tanta habilidad ni conocimiento. Así, uno de los trovadores podrá declararse vencedor sobre su oponente y dejar en el público asistente la impronta de su talento y superioridad. Por otro lado, en el Decimal puede haber dos posibilidades. Por un lado, se pueden improvisar preguntas para el oponente, o utilizar este espacio para responder las preguntas del otro trovador. Por otro lado, hay la posibilidad de que, en algunas intervenciones, se sigan improvisando saludados para el auditorio. Esta última opción otorga la posibilidad de que el Decimal funcione como una forma de contrapunto de la Poesía. El efecto que se logra es anticlimático, ya que, si el tono beligerante sube en la Poesía, en el Decimal esa animadversión baja. En caso de que se mantenga la tensión, la opción que más se utiliza es la del humor, para que la agresividad pueda salir mediante la risa y no genere dificultades mayores en el auditorio. En estos casos el Jarabe se utiliza para que el trovador pueda dejar una impronta de habilidad y respuesta ante el reto del oponente, ya que esos versos también se improvisan (ㅇ). Es decir, el aspecto agónico no se pierde, no es que se acepte la derrota o la incapacidad de responder, sino que se posterga brevemente la respuesta y su repercusión puede ser más contundente, ya que son los últimos versos de la composición y la impronta puede ser más efectiva en la mente de los escuchas. 
Finalmente, en la Despedida, la Poesía retoma un tono cordial y de agradecimiento, tanto para quienes organizaron la topada, los asistentes y el conjunto contrario. Por su parte el Decimal tiene, nuevamente, dos opciones de presentación. Por un lado, puede continuar la poesía de bravata, de aporreón, en la que con humor increpa al contrincante y lo ridiculiza para declararse vencedor de la controversia. Por otro, es un momento en el que se puede retomar un tono cordial y afectuoso. De este modo, la improvisación, que inició con la salutación, concluirá con el deseo de volverse a encontrar y el agradecimiento en la voz de los trovadores.

En esta explicación he intentado mostrar cómo la improvisación se presenta en la pieza arribeña. Un aspecto para considerar es que se alternan versos memorizados con versos improvisados; de este modo, ni uno ni otro aspecto se prioriza en esta tradición, más bien, se da su justo valor tanto al canto oralizado, previamente escrito, cuanto a la creación de versos en el momento. Este aspecto abona de manera importante al tejido caleidoscópico de la controversia poética de esta tradición. Poesía memorial, y poesía improvisada se conjuntan en la voz de los huapangueros y se acompaña con la música que propicia el baile.

En cuanto a la improvisación hay varios factores que son imprescindibles para entender de mejor manera cómo se presenta en esta tradición este elemento. Me parece que el más importante es la contraposición constante, el ir y venir entre la poesía memorizada y la improvisación. Es decir, el trovador debe tener la capacidad recordar los versos que cantará en la Poesía e improvisar los del Decimal en cada una de las composiciones. Las primeras improvisaciones, las salutaciones, tienen la ventaja de que son las primeras de la fiesta. Cuando los trovadores llegan a la parte del aporreón (aproximadamente a partir de las 3 am a las $9 \mathrm{am}$ ), ya puede haber un cierto cansancio. Menciono este aspecto para valorar de mejor forma esta labor, su complejidad en esta tradición y su relevancia dentro de la pieza arribeña.

\section{Versos de controversia}

Para explicar de mejor manera la dinámica de la improvisación en el huapango arribeño retomo la controversia poética entre don Agapito Briones y don Cándido Martínez. Esta fiesta se realizó en Santo Domingo, Villa Juárez, San Luis Potosí, el 16 de diciembre de 1987 con motivo del aniversario ejidal (9). En ese momento, don Agapito Briones ya era un trovador consolidado y don Cándido Martínez estaba en los primeros años de su carrera. Es decir, uno de los atractivos de esta controversia es observar la construcción del discurso y el reto entre un trovador consolidado y otro que está en sus comienzos.

A continuación, presento la glosa y tres décimas glosadas de la $4^{\mathrm{a}}$ intervención del Decimal de la topada, las cuales corresponderían a la sección del Saludo (10). En este momento, la labor más importante es la de complacer al auditorio con las salutaciones que soliciten, hablar de la importancia de la región, agradecer la invitación a esta fiesta o, como en este caso, desarrollar la importancia de la tradición del huapango arribeño para la región y cómo esta tiene una comunicación de ida y vuelta.

\section{Agapito Briones}

San Ciro, bello paisaje, la cuna de un trovador, nunca morirá ese honor que dejó aquel personaje.

\section{Cándido Martínez}

\author{
Que viva y viva el destino, \\ viva esa tierra sin par, \\ todos podemos sembrar \\ el pion* de un campesino (11).
}

En ambas coplas se puede notar un tono cordial y laudatorio hacia el huapango arribeño. Es importante recordar que los trovadores de esta tradición se refieren a su propia labor como un destino (12). En cuanto a la construcción de los versos de don Agapito Briones es de destacar que los dos primeros son, en realidad, frases nominales, en función de vocativo. Este aspecto subraya tanto la tierra a la que se hace referencia, San Ciro, como la labor que cumple al ser "la cuna de un trovador". Aquí habría, además, una clave para comprender la importancia de la palabra destino. El origen y el oficio del poeta se vincula con el lugar de nacimiento. Esto presenta una relación donde el aspecto estético está muy presente. Esta localidad se define como un "bello paisaje", el elemento natural remite a una suerte de lugar idílico que será propicio para que el trovador mítico del huapango arribeño, don Eugenio Villanueva, encuentre los elementos necesarios, no solo para ser trovador, sino también para fundar una nueva tradición de canto, música y poesía. El recuerdo de "aquel personaje" actualiza y muestra la vitalidad de la tradición. Es decir, al rememorar no hay un fuerte elemento nostálgico, por el contrario, hay una 
conciencia de perennidad y reactualización que se vincula con la herencia que se toma y la raíz de esta que se celebra en la música.

La copla de don Cándido Martínez es una estrofa laudatoria cuyo discurso se entreteje discursivamente en sentido contrario al de don Agapito Briones. De este modo, se presenta una de las maneras en las que se puede "dar la vuelta" a la composición del oponente. Si bien ambos tratan el tema en forma de panegírico, don Cándido inicia por presentar la tradición del huapango arribeño y después el orgullo por la tierra. Así, si en la copla de don Agapito Briones queda la impronta de la relevancia del huapango arribeño, en la de Don Cándido Martínez se subraya el campo y el campesinado. Al observar las dos coplas se aprecia que esta relación de elementos contrapuestos se complementa al valorarlos como parte de un mismo discurso. Y, de este modo, el ejercicio laudatorio se presenta con la misma importancia tanto para la tradición del canto como para el lugar donde esto es posible.

A continuación, presento las primeras décimas glosadas de la planta:

\section{Agapito Briones}

La exactitud lo comprueba
de las épocas aquellas
fue un astro entre las estrellas
don Eugenio Villanueva.
El triunfo así se revela
porque fue el astro mayor
de sus versos fue acreedor
yo lo estoy justificando
y siempre adoro cantando
la cuna de un trovador.

\section{Cándido Martínez}

Esos tiempos que pasaron
han formulado una historia
para que con la memoria
esas líneas lo anotaron.
Y los que ahora gozaron
esa tierra del camino
en carácter masculino
a plena solicitud
hoy gozan de una virtud
viva y viva ese destino.

Las dificultades que implica la improvisación, así como una técnica un poco más depurada se presentan en estas dos décimas. Hay una cierta coincidencia en cuanto a la técnica para improvisar este tipo de estrofas que tienen la característica del pie forzado; es decir, que se conoce con cuál verso concluirá la décima (13). Tener una meta en el camino de la improvisación ayuda tanto a conocer el último verso como, cuando hay tiempo, a crear el penúltimo. No se puede perder de vista que el trovador de esta tradición cantó versos memorizados antes de esta improvisación. Es decir, no puede poner su atención con plenitud en la improvisación, ya que requiere recordar también la glosa de línea que dirá antes (14). Por otro lado, cuando se logra crear la décima como versos hexadecasílabos, hay una ventaja en cuanto el sentido, comprensión y estructura de la estrofa. No puede dejar de soslayarse que esta proposición requiere una palabra rimante a la mitad que no tiene eufonía con la palabra que terminará esa proposición. Esta forma de construir la décima, en ideas de versos pareados, propicia una mejor comprensión del mensaje y una mejor línea argumental y discursiva. Sin embargo, la dificultad que presenta esta técnica puede llevar al trovador a guiar su composición no por el camino de buscar ideas hiladas, sino más bien orientarse por la obligatoriedad de la consonancia en las rimas.

Para mostrar otros matices de la improvisación en el Saludo, presento las segundas décimas glosadas de la $4^{\mathrm{a}}$ intervención.

\section{Agapito Briones}

Tenía un canto muy divino
tenía muy bonita voz
por obra y gracia de Dios
fue el que nos trazó el camino
del huapango potosino.
Lo atestiga* un servidor
y dando este pormenor
por eso al estar trovando
su nombre estoy recordando
nunca morirá ese honor.

\section{Cándido Martínez}

En carácter voluntario
en la forma sencilla,
me sugiere la planilla,
el notable comisario,
mandador al escenario,
le quiero manifestar
tan solo para tratar
un ratito de esta historia
recordando una memoria
viva la tierra ni hablar.

Estas décimas laudatorias presentan dos temas relevantes que bien pudieran considerarse de Fundamento. Como el tema de la reunión es un aniversario ejidal, el tema obligado sobre el cual deben 
desarrollar sus composiciones los trovadores es el de la Revolución mexicana. Uno de los protagonistas en la organización del ejido (figura que proveniente del triunfo de la Revolución) es el comisario ejidal. Al saludarlo, don Cándido Martínez alude a este tema y lo resalta como uno de los aspectos sobre los cuales hay que trovar. Por su parte, don Agapito Briones continúa con el panegírico a Don Eugenio Villanueva.

El tema del orgullo por la tierra y la tradición del huapango se muestran también en el tercer conjunto de décimas glosadas:

\section{Agapito Briones}

Hablo con cierta elocuencia

a través de mis esfuerzos

en la rima y en los versos

él nos dejó esta herencia;

por eso con obediencia

en este humilde lenguaje

ante todo el personaje

lo declaro en versería

dando lauros a su valía,

San Ciro, bello paisaje.

\section{Cándido Martínez}

En esta celebración
de un momento positivo
acto conmemorativo
desde aquella iniciación.
Y a plena satisfacción
se pretende recordar
en este hermoso lugar;
en Santo Domingo, aquí,
un verso les canto así
viva y viva este lugar.

Se puede considerar que el saludo en este Decimal, más que a una persona en particular se hace al ejido. Sobre esta idea girarán los versos y será reiterativo, aunque con matices que resaltan características particulares la forma de ponderar el ejido. En este caso, la herencia, lo que se toma de la región y la tradición que está ahí para quien pueda apreciarla y tomar lo mejor de ella. Cuando se decide a admitir el compromiso de ser del lugar, es decir, ser consciente de esta herencia, ya sea porque se nace ahí o porque se reciben de ahí los elementos de la tradición del huapango arribeño se adquiere también un compromiso, una responsabilidad.

Ahora bien, después de este recorrido por el Decimal y de observar cómo se desarrollan los temas del Saludo, bien vale la pena mostrar otra breve selección de poemas que se asocien, en este caso, a la sección del Fundamento. Es importante aclarar, que la Poesía marca con mayor claridad los cambios en las temáticas de las composiciones y el Decimal, en la improvisación, es una suerte de segunda voz, de acompañamiento de la propuesta que se plantea en la primera sección de la pieza arribeña. Con esto en mente, es sugerente realizar un análisis que proporcione más claridad sobre esta labor que cumple el Decimal. Para este propósito presento la glosa y una selección de las décimas glosadas de la $7^{\text {a }}$ intervención de cada uno de los trovadores:

\section{Agapito Briones}

\section{Cuéllar, señor, don Miguel honorable caballero le habla un amigo sincero brindándole este laurel.}
Yo no soy barco de rango se lo dice el que entoniza, de veras le simpatiza la música del huapango, el versito y el fandango; por eso su amigo fiel igual como el aquel se acuerda cuando en Cerritos yo le cantaba versitos, Cuéllar, señor, don Miguel.

\section{Cándido Martínez}

Frente aquí a don Agapito
quiero dar distribución
sobre la Revolución
pero hablando más clarito.
El decirlo es necesario
frente aquí a los personales
señor Amadeo González
me faculta el comisario,
para hacerle un comentario,
aunque fuera en un versito,
lo digo fuerte y quedito
al compás de un pormenor
distribuyendo mejor
frente aquí a don Agapito.

En las décimas que corresponden a la sección de Fundamento en la Poesía hay una suerte de engaño, una máscara que muestra un discurso muy cercano al saludado, pero con algunas marcas textuales que empiezan a entretejer la disputa entre los dos trovadores. Esta cuestión de engaño es muy importante desde varios puntos de vista. Primero, sin duda alguna, que la controversia no es una pelea frontal de un 
trovador contra otro, sino que es un desafío en el que lo más importante debería ser mostrar las cualidades propias para la composición de versos. Segundo, si se enmascara la controversia con una fachada de saludado, se puede hacer caer al contrario en un exceso de confianza y, aunque sin duda pudiera reponerse, la impronta que queda en el auditorio es que está perdiendo la topada. Tercero, muestra que el discurso de victoria se crea desde su opuesto: la supuesta derrota. Cuando se utiliza la fórmula "yo no soy", se puede perder de vista quién la está diciendo. Es decir, si bien hay una suerte de falsa modestia y de captatio benevolentiae en cuanto a que se pudieran cometer errores en la composición, lo dice el trovador, el músico a quien se le confiere la palabra de los cuatros que están en el tarango y a aquel a quien se le invitó exprofeso para esta labor (15).

Presento a continuación, el segundo conjunto de glosas de ambos trovadores de esta sección:

Agapito Briones

Le dice su servidor

al estar versificando

su nombre estoy recordando

porque es persona de honor.

$\mathrm{Y}$ ante esta plana mayor

sin desviarme del sendero

con afecto imperecedero

tengo en su amistad reposo

$y$ tengo un verso jocoso

le habla un amigo sincero.
Cándido Martínez

Aunque yo no soy versero

yo no soy un superior

usted como un trovador

pudo ser algo primero;

por ejemplo de Madero

quiero me dé información

desde aquella iniciación

hablando en este momento

Madero y su nacimiento

quiero dar distribución.

Otros recursos que poco a poco develan la palestra de la confrontación se presentan en estas otras dos décimas. Por un lado, es importante recordar el carácter pícaro de las décimas de controversia. La espada no se desenvaina para atacar de frente, más bien es el uso de la ironía, la sátira y el verso jocoso los recursos que serán fundamentales para que el auditorio considere como superior a un trovador sobre el otro. Aunado a ello, cuando la ridiculización del oponente se hace en estos términos de risa y humor, se va acotando el campo para que su respuesta sea en el mismo sentido. Es decir, se proponen los límites sobre los cuales se va a construir la bravata. Esto se relaciona con el reglamento no escrito de los trovadores; es decir, se plantea una regla fundamental para no ofender al auditorio y para que se mantenga un diálogo entre caballeros.

Cuando la superioridad sobre el otro trovador no se propone desde la ridiculización del contrario, un recurso muy utilizado es el del conocimiento. Esto, me parece, presenta un matiz de sabiduría importante en esta tradición. Por un lado, obliga a que los trovadores que suben al tablado a que se preparen con anticipación; dado que van a cantar poesía memorizada y a improvisar versos, no pueden ser irresponsables con su oficio. Por otro, se muestra a la comunidad que la información que se tenga de un tema, cuando se asimila y se replantea en la voz propia, puede llegar a ser un arma mucho más poderosa que cualquier insulto. De este modo, la lectura de distintos libros y la escritura que practican en sus propias libretas es una actividad muy relevante para cumplir como trovadores frente al auditorio (16). En cuanto al planteamiento de la pregunta, esta puede ser tan específica como se desee. Esto sucede porque se intenta que sea de difícil o imposible contestación y porque, muy seguramente, quien la propone es quien tiene también la respuesta.

Plantear preguntas sería otra señal para mostrar cómo se prepara el camino para la controversia poética entre los dos trovadores. Estas marcas de discurso serían ya una forma de avisar que se está en un momento de transición entre el Fundamento y la Bravata. Es necesario considerar que no hay cortes bruscos en la temática de las décimas. Así, la copla que se glosa carga un peso fundamental: ser un punto de apoyo para que tanto los trovadores como el auditorio tengan señas de identidad sobre la composición que se está desarrollando. Aunado a esto, resulta muy sugerente que, en estas décimas improvisadas, la acumulación de temas: la salutación, el ejido, la importancia de la Revolución mexicana y el enfrentamiento entre poetas muestre el recurso de aglutinación de elementos, de reunir más que de separar temáticamente la controversia. De este modo, se puede apreciar en el análisis una intención de crear un discurso que se enriquece con diferentes matices, pero que no pierde su identidad.

Con la intención de mostrar cuáles son las repercusiones que tiene el uso de estos recursos en el momento de la Bravata y cuáles serían algunos recursos propios de esta sección es que presento ahora la glosa y dos décimas glosadas de esta parte. Debo aclarar que en la grabación, lamentablemente, no 
se alcanza a escuchar con claridad la planta de don Agapito Briones. Aquí los versos:

Agapito Briones

Parece usted una flor

del Paraíso Terrenal

por eso en mi proverbial

quiero rendirle ese honor.

Cual si fuera un ruiseñor

le digo en mis parabienes,

coronándole sus sienes

en mis versos y en mis prosas

con las flores más hermosas

a Margarita Jiménez.

Parece flor de alelía

que apenas abre el botón

y dentro de su inspiración

doy lauros a su valía.

Y matizo la versería,

al estar improvisando,

a brindarle un (...)

en versos y en decimales

haciéndole memoriales

aquí al profesor Fernando.

\section{Cándido Martínez}

Beto Limón, le acredito

Alejandro en mis recados

yo se me hace que Agapito

a mí me hace los mandados.

En la forma y la respuesta

y si el verso analizamos

al cabo el plan empezamos

veremos si nos contesta.

Si quiere juegue una apuesta

esto digo y lo acredito

lo sostengo y lo repito

al compás de esta poesía

Beto Guillén me decía

Beto Limón lo acredito

$Y$ antes del amanecer

es una cosa bonita

y sin el alma marchita

les puedo corresponder.

La mano he de sostener

hablen viento a los recados

en los momentos llegados,

lo digo sin presumir

nos vamos a divertir

Alejandro mi estimado.

La improvisación es un juego de palabras, es un recordatorio de que el dominio del lenguaje no se relaciona con el uso de vocablos rebuscados, sino con el hallazgo que propicia el divertimento. Para ello, sin duda, el trovador necesita que las rimas puedan apoyarlo a crear con tanta libertad como le sea posible dentro de una estrofa restringida. Los recursos de la antítesis, la hipérbole, el oxímoron, entre otros estarán al alcance de aquel trovador que se haya preparado con anticipación, no en la creación de versos para hacerlos pasar como improvisados, sino en el domino y trabajo con las palabras para que pueda surgir un discurso espontáneo y sesudo a la vez. La ironía no es un recurso sencillo de producir, es necesario tener conocimiento tanto del oponente cuanto del auditorio que estará escuchando los versos esa noche para evitar caer en ofensas o en imágenes inapropiadas para el momento.

En estas décimas de don Cándido Martínez la premisa inicial, aunque parece sencilla, es contundente: "Agapito me hace los mandados". Dicha y escuchada como una frase aislada puede caer en la bravuconería y la falta de respeto, de ahí que sea tan importante la glosa, ya que será el recurso por el cual se presenta una línea argumentativa en la que explica o se muestra, según lo decida el trovador, aquellos elementos por los que se tiene superioridad sobre el contrincante. Un aspecto importante será la respuesta que pueda obtener del otro trovador, ya que si no hay respuesta se estará aceptando de forma implícita el planteamiento de la derrota y el servilismo.

Para continuar con el hilo de la Bravata, presento ahora la tercera décima glosada de cada uno de los trovadores:

\section{Agapito Briones}

Usted me va a perdonar me falta colegiatura, Margarita su hermosura es digna de algún altar. Lo digo al improvisar coronándole sus sienes, con flores de los edenes

\section{Cándido Martínez}

Hablando de Callejones

allá en su tierra natal

Agapito es especial

hoy no vale chicharrones.

Sean cual fuere las razones

ahi $^{\star}$ nos vamos al pasito

lo digo fuerte y quedito 
con toda satisfacción

brindo a usted salutación

coronándole sus sienes. cuando el día solo azora

creo yo que contigo ahora

como le dije a Agapito.

Un recurso posible para plantear la derrota del oponente es la reiteración de que carecen de valor sus poesías o, incluso, el trovador mismo. La expresión "hoy no vale chicharrones" presenta que el aludido no merece la atención del auditorio, porque hay un mejor trovador frente a ellos. También se puede entender que tuvo un momento de gloria pasado, pero que ahora hay un nuevo poeta que es superior en todos sentidos. Habrá que subrayar que en las décimas de don Cándido Martínez la sátira que presenta de don Agapito Briones es un tanto medida, no es descarnada ni constante. Una posibilidad de que suceda esto es el respeto que se le tiene por ser uno de los grandes maestros de la tradición del huapango arribeño. Este aspecto, desde el punto de vista de que don Agapito Briones ha planteado la relevancia de los músicos y trovadores que les precedieron, toma un matiz importante, ya que también se le estaría reconociendo, al menos implícitamente, ese lugar de honor.

La presentación de las glosas y las décimas tiene el interés de apreciar, aunque sea de forma sucinta, cómo se construye y presenta el discurso de los trovadores en las décimas improvisadas del Decimal. Con la finalidad de tener un panorama completo de este fenómeno, presento ahora las que corresponderían a la Despedida. Con este propósito transcribo la planta y dos décimas glosadas de la $14^{\mathrm{a}}$ intervención de cada uno de los trovadores:

\section{Agapito Briones}

\section{Roberto Guillén, mi amigo \\ los buenos días le presento colocado en el asiento versando se lo atestiguo.}

Yo le hablo con frenesí en estas mis verserías perdone las tonterías que se me ocurren a mí. Ya no soy lo que antes fui digo en el verso exclusivo dando a su amistad con toda satisfacción brindo a usted salutación, Roberto Guillén, mi amigo.

Le hablo con crecido afán
y dígnese perdonar
no quiero preponderar
ahí* los hechos lo dirán. $_{\text {Y los que vienen y van }}$
dan pruebas de valimiento
en mi perfeccionamiento
le digo en verso y en rima
hoy le canta quien lo estima
los buenos días le presento.

\section{Cándido Martínez}

Se terminó la actuación la despedida les damos adiós, porque ya nos vamos mil gracias por su atención.

Adiós todos los presentes
adiós, esta compañía
nos veremos otro día
se retiran sus sirvientes.
Adiós digo a los oyentes
en esta meditación
abrigo aquí en (...)
se retiran los colegas
dándoles palabras nuevas
se terminó la actuación.
El decirlo en forma plana
creo que decirlo es preciso
son las seis de la mañana
a decirlo me autorizo.
Tenemos un compromiso
allá por otra región
aquí con esta reunión
se terminan los festines
se va Cándido Martínez
y gracias por su atención.

Al llegar el nuevo día, se presenta el ocaso de la topada. Inicio y fin ligados en la voz de los trovadores que estuvieron cantando, discutiendo y agradando al público durante toda la jornada nocturna. Al igual que el cierre de la fiesta, don Agapito Briones es consciente de que su labor como trovador está alcanzando los últimos alientos de su canto, las últimas páginas de sus versos. El tono de reto y de bravuconería que representa declararse vencedor y cantar la derrota del contrario ha dejado paso a la despedida y el abrazo cordial. El adiós se da en un tono muy semejante al que tuvieron los saludados, si en aquel momento se esperaba poder tener la suficiente capacidad para afrontar la empresa que iniciaban, ahora el deseo se centra en volverse a encontrar. Nuevamente, se pide la comprensión del auditorio, la labor de los trovadores los liga con nuevos compromisos que requieren atender. Su retirada no es un acto de descortesía o desdén, es muestra del respeto que le deben también a la comunidad en donde se presentarán próximamente. Así, el auditorio logra entender la importancia de que cese la 
música y que el tiempo de la fiesta ceda su espacio al tiempo cotidiano, aunque es necesario subrayar que, con mucha frecuencia, solicitan que al menos se toquen unos sones más para cerrar el baile, quedar agradecidos por las atenciones y desempeño de los trovadores.

La fiesta termina y el silencio retoma poco a poco el espacio festivo donde se presentaron y enfrentaron los trovadores durante toda la noche. Unos murmullos que poco a poco se apagan dan cuenta de la gente que se despide de los trovadores y los músicos cuando bajan del tarango. El canto, la memoria y la improvisación concluyen dejando un eco en el lugar, una suerte de misiva al futuro que tiene la intención de que la fiesta vuelva a repetirse, que la comunidad encuentre las vías para propiciar este encuentro una vez más. Seguramente, en la mente de los trovadores quedan rimas, versos, incluso habrá alguno que por fin encuentre la combinación más adecuada de palabras para responder el reto del contrario, en vez de aquel momento donde el cansancio, la presión del tiempo y su obligación de contestar no le permitieron tener este hallazgo.

\section{Conclusiones}

El diálogo improvisado presenta una tensión entre los trovadores quienes entablan una suerte de danza que se desarrolla a lo largo del desafío. Las distintas fases en las que la improvisación se lleva a cabo muestran cómo se aceran y se separan en distintos momentos los dos trovadores, agonistas del reto improvisatorio. Cuando hay cortesía entre los trovadores y saludados para los asistentes, sería cuando estuvieran con mayor distancia entre ellos. Al momento de subir el tono de la controversia y lanzar pullas sería un acercamiento entre ambos. Esta danza explicaría el efecto anticlimático de los saludados, un momento menos intenso de la improvisación.

Estos aspectos presentan la complejidad de la improvisación en el huapango arribeño. A pesar de la inmovilidad a la que están determinados por el tarango, los trovadores crean una puesta en escena donde se convierten en rivales por la disposición y el lugar donde se encuentran físicamente, así como por la disposición anímica-profesional de ganar adeptos entre el público. Este último aspecto, tiene un elemento de orden práctico, ya que entre más presentaciones se tengan y mejor hable la comunidad de la habilidad para el canto y la poesía, se podrá tener un ingreso constante debido a la posibilidad de presentaciones recurrentes.

Junto con la teatralidad, primer nivel de ficcionalidad, hay una historia que se desarrolla a lo largo de la jornada que dura la topada: la del duelo entre caballeros. El vaivén de versos propone dos historias paralelas que se desarrollan de manera conjunta. El duelo no es, en principio, un ataque directo, es necesario demostrar conocimiento sobre la tradición, el sentir comunitario, las preocupaciones cotidianas y la fiesta en cuestión que ha reunido a los trovadores. El primer acto de la controversia presenta la cortesanía de los poetas populares, el primer contacto con el auditorio se da en los mejores términos posibles. El segundo acto tensa la cuerda de la controversia, sube su tono y da el espacio para un clímax donde el ingenio, el ataque y el contraataque, el arte de dominar la espada para defenderse y tomar la iniciativa será el hilo narrativo más importante. El desenlace, idealmente, restituye el mundo. La pugna entre los trovadores concluye, la cortesía vuelve para dirigirse al auditorio, a quienes los invitaron a participar en la fiesta y, en la mejor de las situaciones, al oponente.

Un segundo nivel de ficcionalidad concluye al finalizar la controversia: la historia de los cultores populares que se enfrentaron en la noche, en singular batalla, para agradar al auditorio, conseguir adeptos. En términos de la vida cotidiana es posible que este sea el nivel más difícil de diferenciar, no por sus rasgos caracterizadores, sino por las repercusiones que tiene en el ánimo de los trovadores. La topada, en ocasiones ha sido la causa de las confrontaciones entre algunos cultores populares de esta tradición que no ven con buenos ojos la forma en que el oponente los atacó. Incluso se han presentado situaciones donde llega a haber conflicto entre ellos abajo del tablado (17).

Un tercer nivel de poiesis se lleva a cabo a lo largo de toda la noche, la poesía, la música, la palabra construyen en diálogo una obra poética única, irrepetible. No son solo los versos de un trovador o de uno de los grupos de músicos huapangueros los que se deben tomar en cuenta, sino la conjunción de uno y otro grupo, de uno y otro trovador los que se han ido entrelazando a lo largo de la controversia. Los recursos, las estructuras internas, los ritmos y las melodías tejen el gran relato de la topada, aportan al tejido comunitario y recuerdan la importancia de la palabra, su musicalidad, su sentido y pertinencia como elemento fundamental para lograr pasar la noche y encontrar el día, como Sherezade al alargar su 
relato para evitar la muerte. La plaza, el lugar donde se lleva a cabo la performance no se constriñe a límites espaciales necesariamente. Sin duda, las marcas que dan los tarangos son importantes, pero también el espacio donde las parejas se encuentran, bailan y donde se localizan los que atienden con mayor cuidado la poesía de los trovadores son los factores que delimita en realidad ese espacio.

Un cuarto nivel dentro del marco de la improvisación y la controversia poética es la música. En el momento en que el trovador va a improvisar, el ritmo y el volumen de la música bajan. El ritmo constante de la guitarra quinta, que toca el trovador, propicia una continuidad que se puede asociar a los acentos de intensidad del octosílabo. Además, ese ritmo propicia que el cultor popular mantenga un movimiento constante de la mano y esto le ayude a concentrarse de mejor manera para logar encontrar la unidad sintáctica que mejor se acomode a la controversia. Por otro lado, la controversia musical da una vuelta de tuerca sugerente para la fiesta de la topada. No solo el trovador principal se enfrenta, sino que los músicos deben mostrar su virtuosismo y conocimiento sobre los sones que más agradan al público. Cada grupo de huapangueros sobre el tarango conforman un grupo unido, en el que más que solistas, hay un momento para que cada uno pueda hacer notar su valor y pertinencia dentro de la fiesta.

Estas distintas formas de la ficción no se suceden como una suerte de caja china, sino que acontecen a la par uno de otro, al igual que la música, el baile y la poesía se presentan de forma simultánea. Estos elementos conjuntan ese tejido caleidoscopio de la topada, del cual me he centrado ahora, principalmente, en la improvisación. La poesía creada al momento reta al trovador y lo hace caminar en una suerte de cuerda floja. En un extremo está el conocimiento de la tradición y los viejos maestros; en el otro, el conocimiento que tiene sobre el tema de la fiesta y la atención que pone sobre las composiciones de su oponente. La red, por si llegara a caer, es el apoyo del auditorio, aunque será también este aspecto el juez que ponderará la actuación del trovador. Los músicos lo acompañan en esta empresa de la cual saldrá favorecida la comunidad y fortalecida la tradición del huapango arribeño.

\section{Notas}

1. Alexis Díaz Pimienta (2003: 298) encuentra que esta estructura es común en las distintas tradiciones donde se utiliza la décima para la improvisación: "el ritual normalmente está organizado (ese guion implícito, esas leyes no escritas que rigen todo ritual festivo) de manera que los poetas comienzan con una o dos décimas de saludo al pueblo sede, o a los anfitriones, abriendo la zona de tanteo o hilvanación; luego se entienden durante un tiempo indeterminado en la zona de temática núcleo, y, finalmente, llegan a la zona de desenlace, con décimas de despedida que, invariablemente, tienen un carácter tripartito: despedida, resumen y conciliación".

2. Como ya lo he explicado en trabajos anteriores (Rodríguez 2020: 105-106): "En la glosa de línea, el primer verso de la planta remata cada una de las décimas glosadas; esto permite que el número de décimas donde se despliega el tema sea variable y pueda extenderse tanto como lo necesite el cultor, aunque, raras veces, sobrepasan las seis décimas; después de repetir el primer verso, se repiten los demás versos de la copla. En la glosa de cuarteta, cada verso de la planta remata una décima, de este modo, la glosa tiene una restricción mayor, pues solo se puede desarrollar el número de versos que tenga la copla, con mucha frecuencia: cuatro. El verso glosado determina la rima de los versos seis y siete de la décima glosada, en este sentido, tiene similitud con el pie forzado".

3. Según Conrado Arranz (2020: 225), "tanto la festividad como la creación músico-poética que se lleva a cabo en la tradición del huapango arribeño están sujetas a un sistema de normas al que toda la comunidad, y especialmente los propios músicos protagonistas de la performance, se refieren con el nombre de 'reglamento' (...). El 'reglamento', por tanto, constituye una norma consuetudinaria de carácter oral y, a priori, parece inspirada en el derecho natural en cuanto a que aspira, en este caso, a regular la expresión festiva de un pueblo como existencia natural y necesaria".

4. Bajo la égida de Laurette Godinas (2007: 218), "podemos hablar del tópico de la humilitas autorial (...). Siguiendo lo que recomienda Cicerón en su De inventione 'para el cual el poeta debe presentarse en una actitud humilde y suplicante — prece et obsecratione humili ac supplici utemur (I, xvi, 22)—, no es raro encontrar en las coplas del Cancionero alusiones del poeta a su falta de adiestramiento en los menesteres poéticos. Como bien lo señala Curtius, era frecuente en la literatura latina y romance de la Edad Media que el autor se excusara de su rusticitas, su estilo inculto y grosero". 
5. Sobre este matiz de la relación entre la escritura y la voz, Margit Frenk (2006: 161) apunta que "buena parte de la poesía de los siglos XVI y XVII no era una poesía puramente oral: era una poesía que podríamos llamar oralizada, o sea, escrita y luego, a menudo, memorizada y difundida mediante la recitación y el canto. En la vida de los textos poéticos el lado oral era importantísimo, imprescindible, mientras que el lado escrito desempeñaba un papel secundario, de apoyo".

6. Jiménez de Báez (1964: 423) señala que "las décimas de nombres son muy populares en la lírica tradicional española. Posiblemente con anterioridad al siglo XV se conocían composiciones hechas a base de las cualidades de las mujeres y sus nombres.

7. El tarango es una estructura que se encuentra aproximadamente a dos metros del suelo. Es una suerte de banca elevada donde suben los cuatro músicos para la presentación. Otros nombres por los que se conoce a esta estructura son tablado o tapanco.

8. En la controversia poética el trovador puede decidir si se toca un son o un jarabe. En el caso de que se decante por el primero será el vihuelero quien lo interprete. Algunos sones recurrentes son el del Caballito, la Rosita, el Gusto, entre otros. Cuando elige el jarabe, el trovador improvisa una o dos coplas que regularmente siguen la temática de la Poesía o el Decimal.

9. Esta topada se encuentra en el repositorio de la Fonoteca y Archivo del Seminario de Tradiciones Populares que está a cargo de la Dra. Yvette Jiménez de Báez. La grabación original procede de una cinta de audio digital (DAT) bajo la clasificación DAT 670-671. En este repositorio se encuentran también dos copias en casete de esta topada con la clasificación CA 38-46 y C 632-640.

\section{La transcripción completa de la topada se puede consultar en Rodríguez 2020: 227-277.}

11. Sobre los criterios de transcripción es importante decir que las composiciones de don Agapito Briones las he colocado a la izquierda, ya que es quien inició la topada, es decir, es el poeta que "lleva la mano". Las coplas que se glosan las he transcrito en cursivas para distinguirlas de las décimas glosadas, y resaltar el verso que se toma de esta estructura para finalizar la décima correspondiente. Cuando el trovador utilice alguna palabra en la que se altere la morfosintaxis, pero que es significativa para la región la he transcrito con esa variante y he colocado un asterisco $\left(^{*}\right)$ para destacar este elemento.

12. En palabras de don Ascención Aguilar, un viejo trovador de eta tradición, el destino "es una palabra que da a entender varias. Muchas veces dicen que el destino es cosa de la suerte. Entre nosotros los trovadores pensamos que el destino es también un oficio. Todos traemos un don allá de lo alto, nomás que unos lo traemos de un modo, otros de otro; pero toda la criatura que nace trai* un don especial. En mi conocimiento pienso que a veces el destino coincide con el arte, pero de ese destino no siento nada de parte mía, siento que mi persona nomás viene a ser instrumento, que hay un espíritu que nos ilumina. Todos tenemos una gracia muy distinta. Me pongo a veces a hacer un verso y no sé ni cómo le voy a hacer con la guitara afinada y las necesidades que hay entre un público al presentarse, no sé cómo, pero de todos modos hago un verso a la hora que se necesita, a eso yo le nombro inspiración y destino" (véase Velázquez 2004: 243).

13. Alexis Díaz Pimienta explica que "el modo más universal de construir la estrofa improvisada — sea décima, quintilla, copla, octava, etc.- es el modo inverso, de atrás hacia adelante, pero no verso a verso, sino bloque a bloque (...), elabora los versos 9 y 10, el final de la décima (Bloque I), de acuerdo con los signos tomados. Si le da tiempo, elabora también los versos 7 y 8 (Bloque II), de modo que tenga ya la redondilla final completa. Si le sigue dando tiempo (...), entonces salta a elaborar la primera redondilla (Bloque III, o Bloque III y IV) (...). De modo que va dejando para luego, para el final, los versos 5 y 6, el puente (Bloque IV o V)" (2014 523-525).

14. Sobre este aspecto, don Guillermo Velázquez (2004: 88), trovador de esta tradición, apunta que "en la improvisación de la valona hay un gran ejercicio memorístico porque hay que recordar los cuatro pies forzados de la planta para desarrollarlos consecutivamente y hay que incorporar elementos extra que involucren lo que acaba de cantar el contrincante o algo que empieza a suceder en el momento (un pleito, algo chistoso, un repique de campana, o si empieza a llover o si hay una luna esplendorosa, etc. etc.). En los trovadores que se preocupan por la calidad de su improvisación siempre hay un esfuerzo permanente por 'pulir' lo más posible los versos y reconcentrar emociones en ellos que el público comparta e incorpore al disfrute de la fiesta". 
15. Sobre este asunto, Raúl Eduardo Gonzáles (2002: 403-404) comenta que "el cantor declara ante todo que no se considera a sí mismo un poeta ni un hombre estudiado, un recurso retórico: a partir del aparente menosprecio de sí mismo, el compositor popular prepara el terreno para lanzar la ofensa a su rival" (2005: 360).

16. En cuanto a las libretas y la importancia que tienen para los trovadores, Yvette Jiménez constata que "el trovador suele tener una libreta que funciona como bitácora. Frecuentemente, cuando el poema le convence, lo pasará —o se lo pasarán—a su cuaderno o libro personal".

17. Así se aprecia en el testimonio de don Tranquilino Méndez cuando rememora que "con el que fui contrario a rigor, ¡de echarnos la viga!, fue con Julián Castro, un cantador de Diego Ruiz, de sacar su pistola y sacarla yo, nomás que nos apartaron. Agarramos rivalidad porque al terminar una topada me iban a amolar vilmente, y luego, al estar en la mesa desayunando seguimos echándonos la viga, regañándonos boca a boca, aunque ya había terminado la boda. Al despedirnos me dijo: -Mire, jen Diego Ruiz tiene a su padre! — ¡En el Aguacate tiene el suyo —entonces yo vivía allá—, del modo y el pelo que usted guste!" (véase Velázquez 2004: 112).

\section{Bibliografía}

Arranz Mínguez, Conrado

2020 "Trascendencia de las normas de carácter oral y consuetudinario en los rituales festivos populares", Boletín de Literatura Oral (Jaén),nº 10: 219-248.

Berrones, Francisco

1988 Poesía campesina. México D. F., Secretaría de Educación Pública.

Díaz Pimienta, Alexis

2003 "La poesía oral improvisada: un ritual desconocido", en Martin Lienhard (coord.), Ritualidades latinoamericanas. Un acercamiento interdisciplinario. Madrid, Iberoamericana Vervuert: 281-304.

2014 Teoría de la improvisación poética. México D. F., Ediciones del Lirio / Scripta Manet.

Frenk, Margit

2002 "El cancionero oral en el Siglo de Oro", en Poesía popular hispánica. 44 estudios. México D. F., Fondo de Cultura Económica: 159-175.

Godinas, Laurette

2007 "De versos, canciones y coplas: metalenguaje poético y tópicos", en Aurelio González (ed.), La copla en México. México, El Colegio de México: 213-222.

Jiménez de Báez, Yvette

1964 La décima popular en Puerto Rico. México D. F., Universidad Veracruzana.

2002 "Oralidad y escritura: de los cuadernos de trovadores a la controversia, en la Sierra Gorda", en Yvette Jiménez de Báez (ed.), Lenguajes de la tradición popular: fiesta, canto, música y representación. México D. F., El Colegio de México: 395-416.

Rodríguez Hernández, Agustín

2020 La topada de poetas, Boletín de Literatura Oral (Jaén), anejo 4.

Velázquez Benavides, Eliazar

2004 Poetas y juglares de la Sierra Gorda. Crónicas y conversaciones. Guanajuato, Ediciones La Rana.

Velázquez Benavides, Guillermo

2004 "La improvisación en el huapango arribeño", en Improvisación en el mundo (Actas del Encuentro celebrado en Donostia entre el 3 y 8 de noviembre de 2003). Donosti-Bilbo, Euskal Herriko Bertsozale Elkartea: 127-135. 